\title{
Intramural Esophageal Abscess and Dissection due to Retropharygeal Abscess
}

\author{
Joong-Yeon Won, Jin Woo Maeng, Bumjung Park and Sung Kwang Hong \\ Departments of Otorhinolaryngology-Head and Neck Surgery, Hallym University College of Medicine, Anyang, Korea
}

\section{후인두 농양에 의해 발생한 식도 벽내 농양 및 벽내성 식도박리 1예}

원중연 · 맹진우 · 박범정 · 홍성광

한림대학교 의과대학 이비인후과학교실

\author{
Received September 15, 2011 \\ Revised October 24, 2011 \\ Accepted October 26, 2011 \\ Address for correspondence \\ Sung Kwang Hong, MD \\ Department of Otorhinolaryngology- \\ Head and Neck Surgery, \\ Hallym University \\ College of Medicine, \\ 896 Pyeongchon-dong, Dongan-gu, \\ Anyang 431-070, Korea \\ Tel $+82-31-380-3840$ \\ Fax $+82-31-386-3860$ \\ E-mail yeramii@hanmail.net
}

Intramural esophageal dissection is a rare esophageal disorder characterized by sudden severe retro-sternal pain, hematemesis, odynophagia and dysphagia due to longitudinal separation of submucosa from muscle layer of the esophagus. Even though the etiology of this disorder still remains uncertain, it is usually associated with a rapid increase of intra-esophageal pressure in addition to coagulation disorder. We treated a patient who initially presented with retropharyngeal abscess, but finally progressed to an intramural esophageal dissection, which was successfully treated by endoscopic procedure. This is the first case that recorded disease progression and treatment from a retropharyngeal abscess to esophageal dissection.

Korean J Otorhinolaryngol-Head Neck Surg 2011;54:871-4

Key Words Retropharynx $\cdot$ Abscess $\cdot$ Esophagus $\cdot$ Dissection.

\section{서 론}

벽내성 식도박리는 주로 80 90대 여성 노인층에 주로 발생 하는 극히 드문 질환으로 다양한 원인에 의한 식도내압의 갑 작스런 증가나 타박 및 이로 인한 혈종형성에 의해 발생되는 것으로 추정되고 있지만 명확한 원인은 밝혀지지 않았다. 대 부분 갑작스런 흥통, 상복부 불편감, 토혈(hematemesis), 연하 곤란 같은 증상을 주로 호소하는 경우가 많아미이이비인후과 영 역에서 벽내성 식도박리를 경험하는 경우는 드물다. 특히 심경 부 감염의 확산에 의해 2차적으로 발생된 벽내성 식도박리 환 자는 내과나 흥부외과 영역에서도 극히 드문 질환으로 지금까 지 1 건의 문헌보고만 있었으며 ${ }^{2)}$ 경부 전산화단층촬영(computed tomography, CT)에 의해 후인두에 국한된 농양이 확인 되고 이어서 벽내성 식도박리로 진행되어 이를 경부 농양의 배 농술과 함께 식도 내벽의 내시경적 절제술로 치료한 경우는 현 재 전세계적으로도 보고된 바 없다. 저자들은 경부 및 흥부
$\mathrm{CT}$ 를 통해 후인두 농양으로 진단된 79세 여자 환자에서 보존 적 치료를 시행하던 중 지속되는 연하곤란과 더불어 발생한 상복부 통증이 발견되어 종격동염을 감별하기 위해 추가적인 경부 CT를 시행하였다. CT상 후인두 농양의 진행과 이전에 보 이지 않던 상종격동의 연조직염 소견 및 식도의 전장에 걸쳐 발 생한 점막하 농양을 확인하였다. 이에 후인두 농양에 의해 2차 적으로 발생한 상종격동염과 벽내성 식도박리로 진단하고 후 인두 농양의 배농술과 함께 위식도내시경을 이용한 식도 내 가 성 내강 절제를 통해 성공적으로 치료하였기에 문헌고찰과 함 께 보고하는 바이다.

\section{증 겨}

79세 여자환자가 호흡곤란과 목의 불편감을 주소로 응급실 로 내원하였다. 내원 당시 시행한 이학적 검사에서 인두 부위 의 전반적인 부종이 관찰되어 심경부 감염 의심 하에 시행한 
경부 CT에서 하인두, 피열 후두개주름, 후두개 주의공간의 연 조직염과 농양이 관찰되었다(Fig. 1).

후인두의 농양은 입원당일 자발적으로 파열되어 구강으로 자연 배농되었고 환자의 전신적인 상태를 고려하여 항생제 등 의 보존적 치료를 우선 시작하였다. 환자의 증상은 항생제 치 료에도 불구하고 호전되지 않았고 지속적인 연하곤란과 더불 어 상복부의 통증을 호소하여 종격동염으로의 진행을 감별 하기 위해 입원 5일째 다시 시행한 경부 및 흥부의 CT에서 인 두공간, 하악 하공간, 갑상선 주위로의 농양의 확산과 상종 격동의 연조직염 소견과 함께 식도 전반에 점막 하층으로 분 포된 농양이 관찰되었다(Fig. 2). 응급으로 식도 내시경을 시 행하였으며 식도 인두 접합부 직하방에서 식도 내 농양이 자 연 배농되는 소견이 관찰되었고 식도-위 접합부 상방 $5 \mathrm{~cm}$ 까 지 식도 후벽으로 전반적인 부종 소견이 관찰되었다(Fig. 3). 항생제 치료에 반응하지 않고 염증이 진행되는 소견을 보였기 에 수술적 치료를 시행하기로 결정하였으며 심경부 공간의 농양은 경부접근법을 통한 배액을 시행하였고 식도 내 점막 하층의 농양과 벽내성 식도박리는 흥부외과와 내과와 상의하 여 내시경적 가성내강 절제술을 시행하였다(Fig. 4). 수술 중
채취한 농으로 세균 배양검사를 시행하였으나 배양되는 세 균은 없었다. 시술 일주일 후 위식도 내시경 시행하여 시술 부 위 회복을 확인하였으며(Fig. 5), 6개월이 지난 현재 특별한 문 제 없이 외래 추적 관찰 중이다.

\section{고 찰}

경부근막은 경부의 주위 조직을 지지하는 단단한 결체조

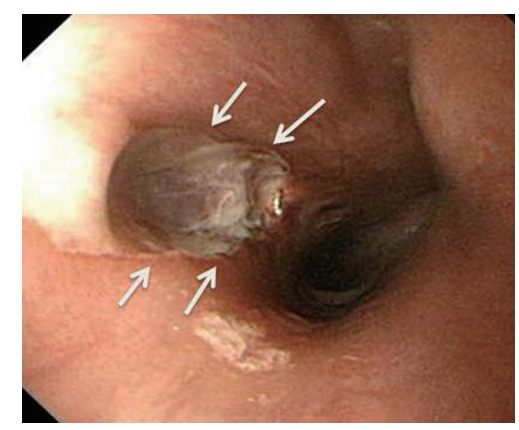

Fig. 3. Endoscopic finding of intramural esophageal abscess. Spontaneous rupture into true-lumen was seen at upper esophageal sphincter (arrows).
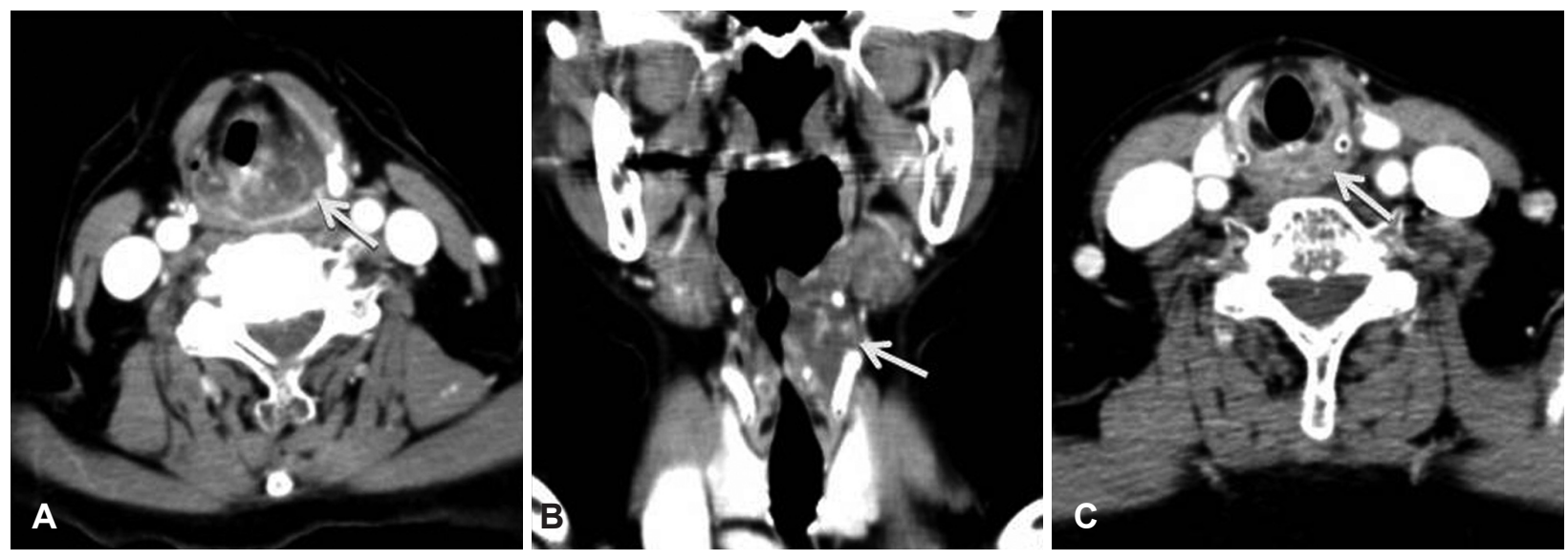

Fig. 1. Contrast enhanced computed tomography $(C T)$ shows abscess formation with cellulites at retropharyngeal wall (A: axial view. B: coronal view). Inflammatory swelling of cervical esophageal wall was observed (C: arrow).
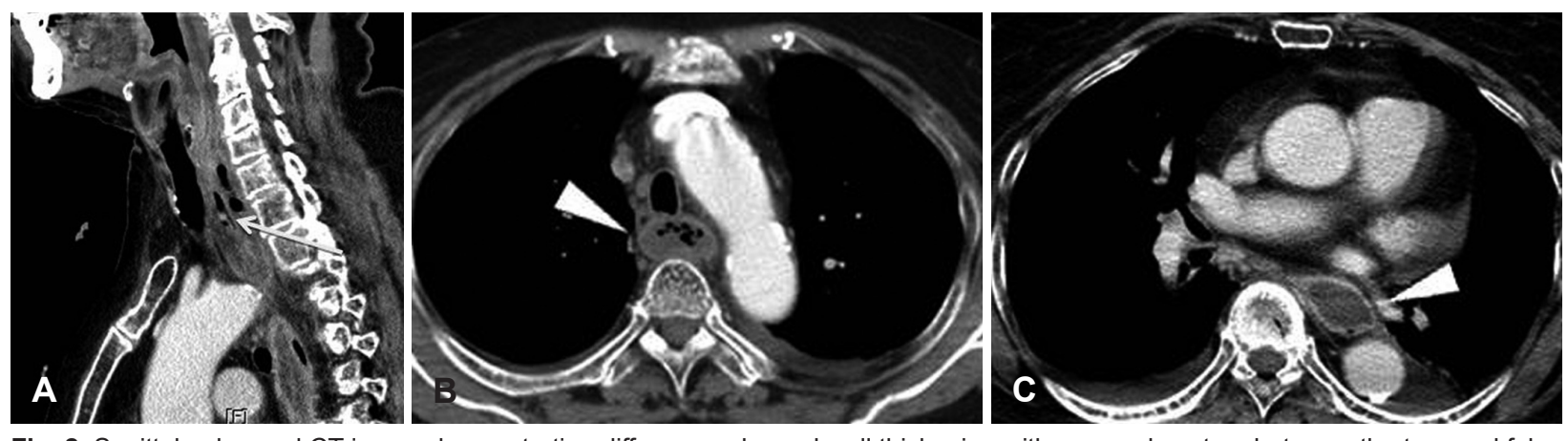

Fig. 2. Sagittal enhanced CT image demonstrating diffuse esophageal wall thickening with mucosal septum between the true and false lumens ( $A$ : arrow). Axial images shows esophageal abscess ( $B$ and $C$ : arrowhead). 

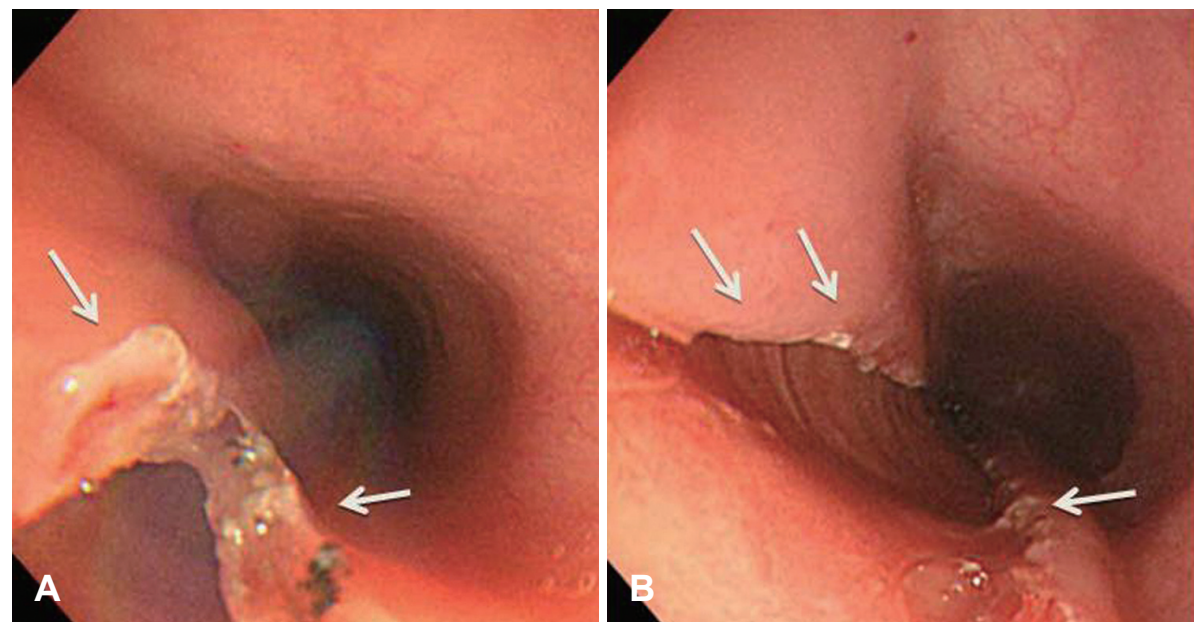

Fig. 4. Endoscopic incision of the false lumens. Endoscopic incision was done with an insulated-tip knife ( $A$ and $B$ : arrows).
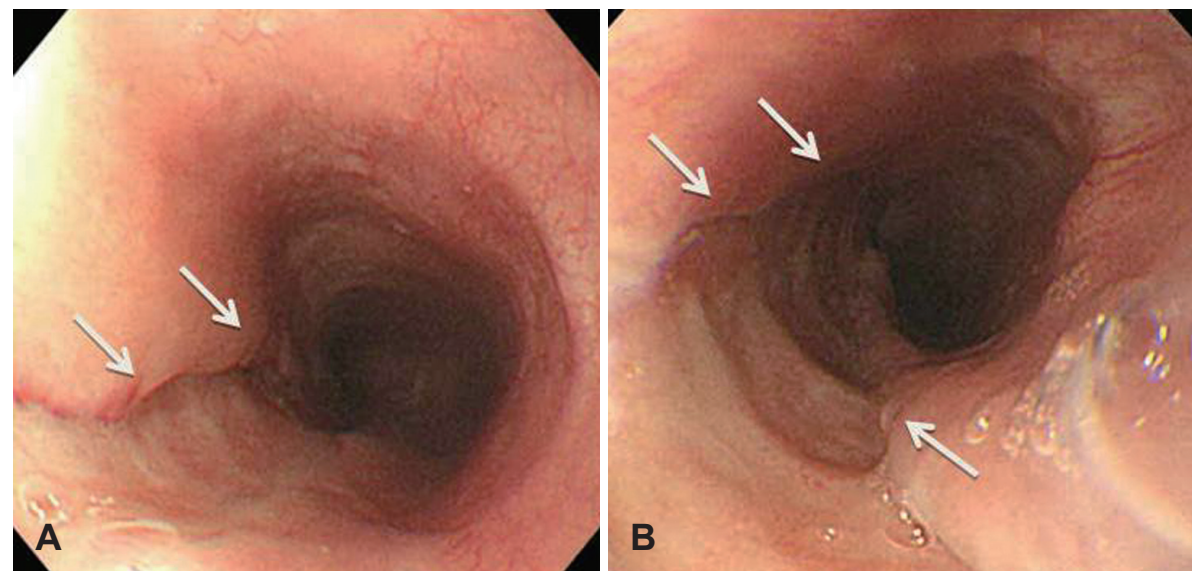

Fig. 5. Follow up endoscopic findings revealed a healing esophageal lumen Two longitudinal mucosal fold-like elevations was observed along the previous endoscopic incision sites (A and B: arrows).

직으로 경부감염의 전파를 막는 역할을 함과 동시에 이를 통 해 감염이 확산될 수 있는 경로를 제공하기도 한다. 심경부 감염이란 경부근막이 둘러싸고 있는 경부근막강 내 농양이 형성되는 것을 의미하는 것으로 ${ }^{3)}$ 설골을 기준으로 상부와 하 부 그리고 상부와 하부 전체에 걸쳐 존재하는 강으로 나눌 수 있다. 본 환자에서 농양소견이 발견된 후인두 공간(retropharyngeal space)은 전척추 공간과(prevertebral space) 위험 공간(danger space)과 더불어 경부 전반에 걸쳐 존재하는 공 간으로 식도의 후부에 있으면서 상부 종격동까지 이르는 공간 으로 이론적으로 상부 경부 감염의 종격동으로의 하행성 확 산에 주된 전파경로로 알려져 있다. ${ }^{4)}$ 특히 고령인 경우나 심 각한 기저질환이 있는 경우 후인두 공간에서의 종격동염으로 의 확산이 많다는 것을 고려하면 ${ }^{5)}$ 수술이나 보존적인 치료에 반응이 없는 경우 후인두 공간을 넘어선 염증의 확산을 감별 해야 할 것으로 생각된다. 또한 해부학적인 관점에서 후인두 강의 전면이(anterior border) 인두와 기관 식도, 갑상선을 둘 러쌓고 있는 내장 근막(visceral fascia)이라는 점을 고려하면 이 공간의 염증은 상종격동염 외에도 기관이나 식도 그리고
갑상선 주위로 확산될 위험이 있을 것으로 생각된다.

벽내성 식도박리는 매우 드문 질환으로 1968년 Marks와 $\mathrm{Keet}^{6}$ 에 의해 처음 보고 되었는데, 대부분 고령의 여자 환자에 서 일어나며 식도의 점막과 점막 하층에 천공이 없는 종적인 분리 양상을 보이며 ${ }^{7}$ 가장 흔한 증상으로는 갑작스런 심한 흥통, 토혈, 연하곤란 등을 호소하는 것으로 알려져 있다. ${ }^{1)}$ 이에 대한 기전으로는 우선 식도점막 내 출혈로 인하여 발생하는 식도박리나 급작스런 식도 내 압력의 변화에 따른 결과라 생 각되고 있으며 기존에 보고된 환자들은 기저질환으로 응고장 애를 가지고 있었으며 내시경 조작이나, 혹은 식도 정맥류의 경화요법이 선행 요인으로 여겨진 경우가 대부분이었다. ${ }^{2,8)}$

그러나 본 증례는 내시경 조작의 기왕력이 없었으며 혈액검 사에서 응고장애를 시사하는 소견도 보이지 않았고 고령 외에 는 특별한 기저질환이 없었기 때문에 이 환자에서 발생한 식도 벽내박리를 이런 기전으로 설명하는 것은 어려울 것으로 생각 된다. 본 증례와 비슷하게 인두 염증으로 인한 2차적인 식도 벽내 박리가 보고된바 있으나 ${ }^{2)}$ 인두농양을 시사하는 초기 CT 소견이 구체적이지 않아 본 증례와 직접적인 비교는 어려울 것 
으로 생각된다.

본 증례에서 후인두 농양에 의해 식도 벽내 박리가 일어난 정확한 기전을 설명하는 것은 어려울 것으로 생각되나 후인두 농양이 2차적인 식도 벽내 박리의 원인이라고 추정하는 근거 는 해부학적으로 후인두강의 전면을 구성하는 내장 근막이 갑상선과 기관 그리고 식도를 둘러싸고 있기 때문에 이를 타 고 염증이 파급될 가능성을 생각해볼 수 있겠고 실제로 처음 시행한 경부 $\mathrm{CT}$ 소견에서 후인두벽의 농양소견과 더불어 이의 확산으로 생각되는 갑상선과 기관 식도 주변에 관찰된 연조직 염 및 농양 소견이 관찰되었으나 경부 식도 내강 자체에는 특 이한 소견이 없었다. 또한 종격동염이 의심되어 다시 확인한 경부 및 흥부 $\mathrm{CT}$ 에서 후인두 부위부터 식도 내강뿐만 아니 라 식도 부위를 포함하는 상종격동까지 염증과 농양이 확산 된 소견이 관찰되었고 내시경에서 식도 벽내 전장에 걸쳐 식도 내강으로 일부 자연 배출되던 농양소견을 보면 식도 벽내 박 리의 원인이 2 차적인 상종격동염으로의 확산에 의한 식도 내 농양에 의해 발생했을 가능성이 높을 것으로 생각된다. 물론 환자가 종격동염으로의 확산이 일어나고 있는 중에 우연히 자 발적인 식도 벽내 박리가 발생하였고 2차적인 염증의 파급으로 식도 내 농양이 생길 가능성이 있을 수 있으나 이를 확인하기 는 불가능할 것으로 생각된다. 또한 이미 식도 내 자연 배농구 가 있는 상태에서 식도 내압의 갑작스런 상승으로 인한 박리도 생각해볼 수 있겠으나 환자는 입원 당시부터 금식을 계속 유 지하고 있었으며 절대 안정을 취하고 있었고 고령 외에는 자 발적인 식도 벽내 박리가 발생할만한 원인인자를 가지고 있지 않았다는 점과 병이 발병하기 이전에는 전혀 다른 문제 없이 건강한 생활을 하고 있었다는 점을 고려하면 가능성은 적을 것으로 생각된다.

기존의 자발적 벽내성 식도박리의 대부분은 금식 등의 보 존적인 치료로 호전되는 경우가 많아 별다른 수술적 처치를 필요로 하지 않는 경우가 대부분이었으며 만약 호전되지 않더 라도 일부 내시경적 절제술과 스텐트 삽입을 통해 치료를 보고 한 경우도 있었다. ${ }^{910)}$ 그러나 본 증례처럼 경부 농양에 의해 2 차적으로 발생된 식도 벽내 농양과 벽내성 식도박리를 치료 하기 위한 구체적인 지침이 없었기에 일반적인 경부농양의 치 료원칙하에 보전적인 치료보다는 좀더 적극적인 치료를 시행 하기로 결정하고 경부농양의 배액술과 내시경적 식도 내 가성 내강의 절제를 통한 식도 내 농양 배액술을 시행하였다. 시술 후 환자의 증상은 급격하게 호전되었으며 시술 2주 후 퇴원하
여 현재 외래 추적 관찰 중이다.

결론적으로 본 증례는 심경부의 염증의 확산에 의한 식도 벽내 농양과 이로 인한 식도 벽내 박리를 보고한 극히 드문 경우로 생각되며 후인두 공간의 농양이 식도 내로 파급된 경 로에 대해서는 후인두강의 전면을 구성하고 있는 내장근막을 따라 식도벽의 점막하층을 타고 확산되었을 것으로 추정된 다. 그러나 이 환자의 증례만으로 이에 대한 명확한 결론을 내리기에는 근거가 부족할 것으로 생각되며 이는 추후 다른 증례나 연구를 통하여 보완되어야 할 과제로 생각된다. 또한 본 증례는 보존적인 치료에 반응이 없었기 때문에 후인두 간 의 농양의 배액술과 내시경적 식도 내 가성 내강 절제술을 통해 환자를 성공적으로 치료하였으나 이를 일률적으로 적 용하기는 힘들고 상태에 따라 적절한 치료방법을 선택해야 할 것으로 생각된다.

\section{Acknowledgments}

The authors thanks Prof. Kyoung-Oh Kim (department of gastroenterology) and Kunil Kim (department of thoracic and cardiovascular surgery) for counsel about treatment plan.

\section{REFERENCES}

1) Gluck M, Jiranek GC, Low DE, Kozarek RA. Spontaneous intramural rupture of the esophagus: clinical presentation and endoscopic findings. Gastrointest Endosc 2002;56(1):134-6.

2) Benatta MA, Grimaud JC, Kaci M, Desjeux A, Baghdadi M, Loumi A. Intramural esophageal dissection due to pharyngeal abscess treated by endoscopic esophageal transection: a case report. Gastroenterol Clin Biol 2010;34(4-5):329-31.

3) Levitt GW. Cervical fascia and deep neck infection. Otolaryngol Clin North Am 1976;9(3):703-16.

4) Marty-Ane CH, Alauzen M, Alric P, Serres-Cousine O, Mary H. Descending necrotizing mediastinitis. Advantage of mediastinal drainage with thoracotomy. J Thorac Cardiovasc Surg 1994;107(1):55-61.

5) Lee JK. A clinical study of fourteen cases of deep neck infection with mediastinal involvement. Korean J Otorhinolaryngol-Head Neck Surg 2005;48(5):636-40.

6) Marks IN, Keet AD. Intramural rupture of the oesophagus. Br Med J 1968;3(5617):536-7.

7) Younes Z, Johnson DA. The spectrum of spontaneous and iatrogenic esophageal injury: perforations, Mallory-Weiss tears, and hematomas. J Clin Gastroenterol 1999;29(4):306-17.

8) Mathieu B, Le Gall P, Mourani A, Marquand A, Schaefer JP. [Socalled spontaneous intramural dissection of the esophagus]. Gastroenterol Clin Biol 2000;24(11):1117-21.

9) Kim SH, Lee SO. Circumferential intramural esophageal dissection successfully treated by endoscopic procedure and metal stent insertion. J Gastroenterol 2005;40(11):1065-9.

10) Cho CM, Ha SS, Tak WY, Kweon YO, Kim SK, Choi YH, et al. Endoscopic incision of a septum in a case of spontaneous intramural dissection of the esophagus. J Clin Gastroenterol 2002;35(5):387-90. 